\title{
LETTERS
}

\section{Physicians need to participate in developing standards for electronic health records}

It is great to see all the responses to the editorial by Dr. Persaud in CMAJ. ${ }^{1}$ My feeling is that rather than choosing a singlevendor solution, the thing to do is to standardize the data elements and the architecture of the records. A lot of work has been done on this by international organizations like Health Level Seven International ( $\mathrm{HL} 7)$ and International Organization for Standardization (ISO). Canada participates at these meetings, but the challenge seems to be how to get that knowledge to the level of the developers of electronic health records and to the users of these records.

I have been to many meetings related to computer-based health records where no one had heard of ISO 10781, 13606 or 18308. These documents provide extremely detailed information on standards for health information. Physicians, in general, are only interested in having something that works. The problem is that although they may be unhappy with how their system works, they may be unwilling to spend any time informing their vendors about problems. There are many simple things that could be done to reduce some of the stress that these electronic health records are causing, but it seems to take decades to get anything done that is of substance.
A major problem is the organizations that produce the documents that are imported into the physicians' electronic health records. These organizations are using systems that were developed in the last century, and there seems to be little pressure to get them updated.

I agree that physicians should not have to be involved with the deep-in-theweeds technical details. However, the developers of electronic health records have not really been involved either. There seems to be a preference to make things up as they go along. There is a need for at least a few physicians to provide guidance on a number of important issues like what a problem list should look like and how it should function, how should laboratory results be displayed and grafted, and how to deal with prescriptions that are written but never filled. These are just a few examples that need to have clinician input. I recognize that these are not simple tasks, as I have witnessed day-long arguments on problem list issues.

I think that the solution does not rest with either a single vendor or multiple vendors. Having switched from 1 vendor to a different vendor, I can say that it was difficult and will become more difficult as more data are accumulated. I believe that the solution is to get agreement on what the architecture for electronic health records should be, with standardized data elements and clinical terminology. A comprehensive and detailed document of specifications was developed in British Columbia, but there has been a great deal of reluctance to incorporate the recommendations into the current electronic health records. ${ }^{2}$

Solutions to these issues are long overdue. Considering that the major vendors of electronic health records have users across the country, what are our national organizations doing to get things to move forward?

\section{Raymond Simkus MD}

Family physician, Brookswood Family

Practice, Langley, BC

- Cite as: CMAJ 2019 May 27;191:E588. doi: $10.1503 / \mathrm{cmaj} .71920$

\section{Reference}

1. Persaud N. A national electronic health record for primary care. CMAJ 2019;191:E28-9.

2. EMR-to-EMR data transfer \& conversion (E2E-DTC) standard. Part II - Consolidated CDA implementation guide. Vancouver: BC Information Technology Office; 2013. Available: www2.gov.bc.ca/ assets/gov/health/practitioner-pro/pito-e2e-dtc -part2-consolidated-implementation-guide.pdf (accessed 2019 Apr. 16).

Competing interests: Ray Simkus has worked on health information standards with Canada Health Infoway, HL7, SNOMED International and ISO. He has worked with several vendors and used various medical software brands in his medical practice. No other competing interests were declared. 